\title{
Processos Formativos e mediação em centros e museus de ciências: o caso de um centro de ciências de Vitória/ES
}

Jonathan Pires Janjacomo*, Geide Rosa Coelho**

\section{Resumo}

A pesquisa tem por objetivo compreender os processos formativos que influenciam na constituição dos sujeitos quanto aos seus saberes e fazeres da mediação em um centro de ciências. Para alcançar o objetivo assumimos como delineamento metodológico o estudo de caso e como sujeitos os mediadores de um centro de ciências de Vitória - ES. Os dados foram produzidos por meio da participação como mediador voluntário do primeiro autor dessa pesquisa que realizou duas rodas de conversa que foram gravadas em áudio e posteriormente transcritas. Os dados foram analisados a partir do referencial freiriano em articulação com os saberes docentes e os saberes da mediação em centros de ciências. Os resultados demonstraram influência das mídias eletrônicas como fonte de inspiração bem como os processos de escolarização, principalmente no que se refere aos saberes pedagógicos. Outro aspecto evidenciado é o processo de formação centrado na autoformação dos mediadores.

Palavras-chave: Processos formativos. Saberes da mediação. Centro de ciências

* Licenciado em Física, Mestre em Educação pela Universidade Federal do Espírito Santo, Doutorando em Ensino de Física no Programa de Pós-Graduação Interunidades em Ensino de Ciências- USP. Brasil. E-mail: janjacomo1991@gmail.com

* Licenciado em Física, Mestre em Educação e Doutor em Educação pela Universidade Federal de Minas Gerais. Professor dos programas de Pós-Graduação em Educação (PPGE-UFES) e do Programa de Pós-Graduação em Ensino de Física (PPGEnFis-UFES) da Universidade Federal do Espírito Santo. Brasil. E-mail: geidecoelho@ gmail.com 


\section{Introdução}

Centros e museus de ciências são considerados espaços de educação não formal e se destacam por apresentarem ao público ambientes propícios ao diálogo entre as ciências da natureza e a cultura científica. Em alguns países, os centros e museus de ciências são tidos como locais de diversão familiar, sendo um dos principais programas a se fazer em um dia de lazer ou para programações especiais como observações astronômicas noturnas, acampamento e festas de formaturas (JACOBUCCI, 2008). Entretanto, no Brasil a ideia de que museus são locais em que se guardam velharias é predominante no imaginário e no discurso popular e, por isso, segundo Codes, Silva e Araújo (2011), menos de um terço da população nacional já visitou algum tipo de museu e quando se trata dos museus de ciências, certamente o quantitativo é ainda menor.

Hamburger (2001) sinaliza que temos poucos centros e museus de ciências no país e a maioria deles são recentes. Além disso, há pouca divulgação sobre as atividades que ocorrem nesses espaços. O contraponto é visto nos dados levantados pela Associação Brasileira de Centros e Museus de Ciências (ABCMC), que em seu guia de instituições no país, aponta para o crescimento no número de instituições, aumentando em mais de $40 \%$ o número de locais cadastrados entre 2009 e 2015.

Associado a esse crescimento, expandem-se também as pesquisas com o enfoque nos centros e museus de ciências. Um amplo levantamento realizado por Ovigli (2015) demonstrou que o aumento se deu a partir do início dos anos 2000, indicando alguns eixos categóricos nos quais têm se centrado as investigações. Para Ovigli (2015), há um conjunto de trabalhos que versam a respeito dos aspectos pedagógicos de estruturação de mostras científicas e ações de divulgação científica, outras pesquisas buscam compreender como se dá a aprendizagem nos museus de ciências. Estudos que focam na formação de professores têm tratado de investigar a contribuição dos museus na formação dos educadores, além de trabalhos que discutem a formação dos próprios educadores nos espaços científico-culturais, este último ponto de discussão deste artigo.

Em geral, centros e museus de ciências oferecem formações aos profissionais que ingressam para compor o quadro de mediadores, como é possível constatar em diversos capítulos dos livros: Educação para a ciência, de Crestana e colaboradores (2001) e Diálogos e ciência, de Massarani e colaboradoras (2007). Quando analisamos algumas destas pesquisas que descrevem os processos formativos de media- 
dores em centros e museus de ciências, notamos que boa parte das características profissionais são adquiridas no exercício da atuação como educador museal e não na formação inicial. Gomes e Cazelli (2016) refletem sobre a intencionalidade da formação a partir da experiência, que ocorre quando os educadores compreendem as demandas de seu ofício no conflito com a realidade -, questionando se essa se constitui como um ato intencional da instituição ou se é influenciada por limitações de tempo, orçamento e outros, dentro da formação inicial dos mediadores.

Ainda que alguns exemplos possam ser encontrados, “a literatura na área de formação de educadores que atuam direta e indiretamente nos espaços de educação não formal ainda é muito escassa no país" (COELHO; BREDA; BROTO, 2016, p. 528), dessa forma delineamos como objetivo central deste artigo compreender os processos formativos que influenciam na construção dos sujeitos quanto aos seus saberes e fazeres da mediação em um centro de ciências.

\section{Mediação humana em espaços científico-culturais}

Os centros e museus de ciências são espaços que buscam dialogar sobre os empreendimentos científicos da humanidade junto a seus visitantes e o mesmo acontece, na maioria das vezes, pela voz de seus mediadores humanos. A mediação na abordagem sociocultural é compreendida como um processo de produção de relações entre objetos, fenômenos e contexto com o ser humano, promovendo uma ação reflexiva, crítica e construtiva entre sujeito e mundo.

Podemos analisar a mediação em museus de ciências sob diferentes perspectivas, a primeira delas é a mediação pedagógica, em que a construção do conhecimento ocorre pela via do diálogo, forma de interação que requer compromisso e respeito com os saberes prévios dos visitantes. Essa visão vai ao encontro do referencial freiriano (FREIRE, 1988), compreendendo que a educação é fruto de fala e escuta, de uma visão horizontal entre educador e educando, e não em um processo de transferência de conteúdo.

Se entendermos mediação como a mera transmissão de conhecimento de um indivíduo que sabe para outro que não sabe, corremos o risco de transformar a mediação em um processo de mão única, sem diálogo e sem levar em consideração as peculiaridades do receptor da informação, protagonista e agente, tanto quanto o mediador, e dessa forma estaríamos esvaziando os sentidos dos processos de ensino e aprendizagem (PINTO; GOUVÊA, 2014, p. 57). 
Outro olhar possível considera que a mediação é o agente da transformação cultural em cada sujeito, modificando sua percepção de mundo a medida que o objeto é compreendido por ele. Dessa forma, a mediação cultural é entendida como uma “aproximação entre dois mundos culturais, tendo como meta não a substituição ou a superposição de um meio de cultura em detrimento de outro, mas a mudança do homem e do mundo" (PINTO; GOUVÊA, 2014, p. 56).

Essa mudança é possível a partir do encontro entre os sujeitos e suas culturas, momento em que as observações, constatações, descobertas e emoções são elementos que se misturam nos museus de ciências, tornando o local um ótimo ambiente para se conversar sobre ciência. Para Wagensberg (2001) esse é um dos elementos que dá vida ao museu: o diálogo entre os visitantes estimulados pelo que presenciam e a necessidade humana de compartilhar o que aprende, bem como o ato de reinterpretar e, dar novos significados para o que vive. "O museu se torna um centro onde pessoas se reúnem para conversar, um lugar que celebra a riqueza das experiências individuais e coletivas, e um participante da solução de problemas de forma colaborativa" (HIRZY, 2002, p. 10, apud RODARI; MERZAGORA, 2007, p. 9).

Para Pavão e Leitão (2007), tudo isso é possível graças a presença dos mediadores e das mediadoras, sujeitos cujo papel é o de estimular a curiosidade nos visitantes. Nesse sentido, os autores denominam as interações que ocorrem como sendo explainers-on, ou seja, "reconhece o papel do monitor dentro do museu como instrumento interativo por excelência, com potencial invejável para mediar processos de construção do conhecimento" (PAVÃO; LEITÃO, 2007, p. 41).

Com tanto a desafiar e problematizar, os museus de ciências são locais ideais para a condução no visitante de uma curiosidade ingênua a uma curiosidade epistemológica (FREIRE, 2006), gerando muito mais dúvidas boas, uma vez que consideramos que "o visitante deve sair com uma interrogação maior do que aquela que ele trouxe [...] oferecer respostas sim, mas, sobretudo gerar a indagação" (PAVÃO; LEITÃO, 2007, p. 41). Nesse sentido, um dos papeis do mediador e da mediadora é fazer a aproximação entre o mundo da ciência e o do visitante, independentemente de sua origem, em outras palavras o mediador é "aquele que transita por vários mundos, repletos de modelos diferenciados: da ciência, dos visitantes e dos idealizadores das exposições e atividades” (QUEIRÓZ et al., 2002, p. 79), além de seu próprio mundo. 


\section{Formação de educadores e seus saberes}

As pesquisas em/sobre/com centros e museus de ciências têm se expandido nos últimos anos (OVIGLI, 2015), entretanto não há um referencial específico que trate da formação de mediadores (GOMES; CAZELLI, 2016) e, por isso, é comum encontrarmos trabalhos que utilizem interlocutores da área da formação de professores.

Com a intenção de ampliar a maneira como compreendemos a formação de mediadores em centros e museus de ciências, fazemos algumas considerações acerca dos processos formativos que originam os saberes necessários à mediação em museus. A obra de Tardif (2002) intitulada "Saberes docentes e formação profissional", possibilita ampla compreensão a respeito da origem dos saberes para atuação como educador, sendo considerado por nós como um bom balizador para as análises de dados desta pesquisa. A partir da visão de Tardif (2002, p. 36), é possível "definir o saber docente como um saber plural, formado pelo amálgama, mais ou menos coerente, de saberes oriundos da formação profissional e de saberes disciplinares, curriculares e experienciais".

Além da constituição como educador, os processos formativos influenciam e são influenciados pelas matrizes político-filosóficas dos sujeitos, assim sendo trazemos as concepções apresentadas nas obras de Paulo Freire, com ênfase para a "Pedagogia da autonomia: saberes necessários à prática educativa” (FREIRE, 2011). Algumas aproximações e distanciamentos serão feitos entre as obras referidas e outras que dialogam mais especificamente sobre/com centros e museus de ciências.

Como já citamos não há um referencial específico sobre a formação de mediadores, porém, no que tange aos processos de mediação, Queiróz e colaboradoras (2002) estabeleceram os saberes da mediação em museus de ciências e suas relações com 0 contexto escolar. Para as autoras, existem as seguintes categorias e subcategorias:

I) saberes compartilhados com a escola - saber disciplinar, saber da transposição didática, saber do diálogo e saber da linguagem; II) saberes compartilhados com a escola no que dizem respeito à educação em ciência - saber da história da ciência, saber da visão de ciência, saber das concepções alternativas; III) saberes mais propriamente de museus - saber da história de instituição, saber da interação com professores, saber da conexão, saber da história da humanidade, saber da expressão corporal, saber da manipulação, saber da ambientação e saber da concepção da exposição (QUEIROZ et al, 2002, p. 81).

A internalização dos saberes requer tempo, pois "a dimensão temporal está relacionada com as situações de trabalho que exigem dos trabalhadores conhecimentos, 
competências, aptidões e atitudes específicas que só podem ser adquiridas e dominadas em contato com essas mesmas situações” (TARDIF; RAYMOND, 2000, p. 211).

A condição de educando demanda tempo e fontes de conhecimentos diversificadas, nesse contexto os/as mediadores/as devem se deixar abertos a novas experiências e práticas que lhes sejam significativas para sua formação. Freire (2011) sinaliza que aos educadores se colocarem conscientes de que estão em constante construção de seus saberes, pode-se e deve-se sempre buscar mais e ir além, dessa forma o tempo vivenciado se caracteriza como possibilidade de experiência profissional, desde que seja acompanhado de reflexão crítica da realidade e elaboração de novos meios de se estar profissional frente às demandas.

Considerando o ofício do mediador sujeito a múltiplas interferências durante toda sua vida profissional, parece ficar clara a ideia de que a formação, inicial ou continuada, não deve se ater aos aspectos meramente técnicos, apesar de não se desejar que estes sejam renegados (QUEIRÓZ et al., 2002).

Ao se analisar o pensamento de Tardif e o pensamento freiriano, o primeiro autor traz a importância e influência da esfera social na qual os profissionais da educação estão inseridos, sendo vital na vida de professores e mediadores. Trazemos uma síntese do que é proposto por Tardif quanto aos saberes dos professores, suas fontes sociais e os modos de integração no delineamento da profisssão.

Os "saberes pessoais dos professores" (TARDIF, 2002, p. 63) são aqueles relacionados à família, ao ambiente em que se vive, à educação que trazemos "de casa", dentre outros, que são incorporados ao longo da vida e compõem os caminhos que são percorridos quanto aos modos de ser educador. Os "saberes provenientes da formação escolar anterior" se constituem como o conjunto de conhecimentos adquiridos em mais de uma década em que o sujeito é estudante e, que podem influenciar em sua visão de educação. Os "saberes provenientes da formação profissional para o magistério" se configuram em cursos de formação em licenciatura, desde as disciplinas cursadas, até os cursos de formação continuada, passando por estágios entre outros. Os "saberes provenientes dos programas e livros didáticos usados no trabalho" se referem à adaptação realizada durante a prática docente quanto aos dispositivos que são disponibilizados, tais como livros didáticos, cadernos de exercícios, avaliações externas e outros. Os "saberes provenientes de sua própria experiência na profissão, na sala de aula e na escola" dizem respeito à socialização no exercício da profissão, nas trocas de saberes com os colegas de profissão, nos momentos de planejamento 
e reuniões com todo o corpo docente, o que proporciona uma noção ampla de como é/está a instituição educacional.

Na visão do autor, diversos saberes mobilizados pelos educadores em seu cotidiano não são provenientes de suas formações especializadas para a prática profissional, mas advêm de outros processos formativos. Pensar dessa forma exige que os educadores e educadoras se coloquem no papel de reflexão crítica sobre suas práticas a fim de reconhecer os conhecimentos que são transformados em saberes necessários à sua atividade educacional (ABRAHÃO, 2016). Podemos entender esses saberes como provenientes de diferentes contextos socioculturais que influenciam nas atividades de mediação realizadas e produzidas pelos sujeitos, ou seja, a matriz política, social e cultural influencia e define a postura tomada pelos mediadores (FREIRE, 1979).

Dentre as fontes de conhecimento, há um consenso de que é no espaço de atuação que se formam as principais bases para um trabalho transformador. No processo de formação permanente, o momento da aprendizagem do educador é o da reflexão crítica com a prática, o ato de se assumir como sujeito inconcluso em seu campo de atuação, uma vez que "na concepção de Freire, teoria e prática são inseparáveis tornando-se, por meio de sua relação, práxis autêntica, que possibilita aos sujeitos reflexão sobre a ação, proporcionando educação para a liberdade" (FORTUNA, 2015, p. 65).

Por isso é que, na formação permanente dos professores, o momento fundamental é o da reflexão crítica sobre a prática. É pensando criticamente a prática de hoje ou de ontem que se pode melhorar a próxima prática. O próprio discurso teórico, necessário à reflexão crítica, tem de ser de tal modo concreto que quase se confunda com a prática (FREIRE, 2011, p. 40).

Se nas obras freirianas não há uma sistematização a respeito da origem dos saberes utilizados por educadores, Carvalho (2014) fez uma aproximação da maneira como os conceitos surgem na literatura de Paulo Freire e são categorizadas por Nóvoa (1999), apresentando-as da seguinte maneira:

Saberes específicos (ou saberes das disciplinas), da própria disciplina de atuação do docente, oriundos de sua formação profissional inicial, necessários à interpretação dos conteúdos curriculares; Saberes didáticos (ou saberes da pedagogia), também originários de sua formação inicial, necessários ao entendimento das teorias pedagógicas e ao planejamento das atividades didáticas; Saberes experienciais (ou da experiência), frutos de sua vivência profissional, a fim de tornar exequíveis as estratégias didáticas planejadas; Saberes vivenciais, ou seja, todas as experiências impressas pelo meio social no consciente e inconsciente do professor ao longo de sua trajetória desde a infância (CARVALHO, 2014, p. 36-37). 
Um primeiro olhar para as categorias acima pode dar a impressão de que são as mesmas, ou ao menos semelhante, às de Tardif (2002). Porém, a diferença está no fato de que a formação do profissional na perspectiva freiriana tem como elemento central o caráter político do ser educador.

A construção de um arcabouço de soluções oriundas de percursos pessoais e profissionais tem o poder de mudar a concepção sobre o estar no mundo e, com isso, tem mais relação com a prática de uma educação libertadora, educação que visa dar subsídios para os enfrentamentos cotidianos. Dessa forma, “[...] ensinar já não pode ser este esforço de transmissão do chamado saber acumulado, que faz uma geração à outra, e aprender não é a pura recepção do objeto ou do conteúdo transferido" (FREIRE, 1997, p. 5). O mediador como ser dialógico, deve saber escutar o que o outro tem a dizer e saber dizer o que o outro precisa escutar, com a plena ciência do momento de intervir para não atrapalhar, mas sim ajudar o

[...] indivíduo a "construir" a sua interpretação pessoal, individual, da realidade da sua existência, o que, de forma alguma, implica numa contínua "reinvenção da roda", mas, isto sim, numa oportunidade do indivíduo dar significância à realidade que o circunda [...] e que, por vezes, passa ignorada (CARVALHO, 2014, p. 40).

Todos os processos formativos mencionados, são assimilados por mediadoras e mediadores de centros e museus de ciências e se tornam fundamentais para a sua atuação diária, ainda que se transformem a partir de novas experiências. É com esse olhar que pretendemos, analisar as narrativas produzidas com os mediadores e as mediadoras que atuam em um museu de ciências.

\section{Delineamento metodológico}

o presente trabalho configura-se como um estudo de caso, pois dessa forma é possível "focalizar um fenômeno particular, levando em conta seu contexto e suas múltiplas dimensões", valorizando "o aspecto unitário" e ressaltando "a necessidade da análise situada e em profundidade" (ANDRÉ, 2013, p. 97).

Dentro do estudo de caso, alguns métodos foram utilizados na produção dos dados, tal como o da atuação do primeiro autor deste trabalho como mediador voluntário na Escola da Ciência - Física (ECF), a fim de possibilitar a produção de diários de campo reflexivos entre os meses de junho e setembro de 2017. Além de estar presente no centro de ciência em seu pleno funcionamento, esse método pos- 
sibilitou uma aproximação afetiva com os educadores que atuam no espaço, o que foi de fundamental importância para evitar "desconfianças iniciais e estabelecer uma relação franca, indispensável ao fornecimento, por parte dos investigados, de dados o mais aproximado possível à sua realidade" (GALVÃO, 2005, p. 342).

Outro método utilizado foi a formação de rodas de conversa (MOURA; LIMA, 2014), ferramenta que possibilita a produção qualitativa de dados, uma vez que no ato de conversar pode-se observar e refletir com as narrativas dos sujeitos e, simultaneamente, possibilita um processo formativo para todos participantes, uma vez que refletimos sobre a nossa prática pedagógica e profissional ao narrarmos (ABRAHÃO, 2016).

No caminho que delineamos, a fuga do objetivo dos estudos esteve sempre presente, uma vez que os mediadores conversavam não só sobre o tema proposto, mas sobre tudo que tem relação com ser um mediador em um centro de ciência. A conversa também possibilitou a abertura ao novo, encontros com o diferente enunciado por seus colegas e interação com o próprio espaço, criando diversos pontos de escape, mas que sempre retornavam de maneira fluida e natural.

De certa forma podemos dizer que as rodas de conversa se caracterizaram como momentos em que os mediadores desataram alguns nós que estavam amarrados em suas gargantas e que esse exercício de fala e escuta foram se construindo nas idas e vindas das memórias de cada um. As narrativas produzidas nas rodas são contextualizadas e locais, nos dando a possibilidade de responder ao nosso problema de pesquisa. Acreditamos que a ênfase do local onde foi realizada a pesquisa é necessária, pois consideramos apenas os elementos do caso que estudamos, assim não pretendemos generalizar para outros espaços, uma vez que "a generalização é sempre problemática, não podem ser considerados gerais, fatos dizendo respeito a contextos muito particulares" (GALVÃO, 2005, p. 331).

Foram realizadas duas rodas de conversa com os mediadores da ECF no próprio espaço físico do acervo, nos dias vinte e nove (29) de julho de 2017 e dois (02) de setembro de 2017. Além do pesquisador/mediador voluntário, na primeira roda de conversa houve a presença de cinco mediadores e quatro mediadores na segunda. As duas rodas de conversas foram gravadas em áudio para posterior transcrição e análise. Todos os mediadores participantes da pesquisa assinaram o termo de consentimento livre e esclarecido'. 


\section{Sobre a Escola da Ciência _ Física e os mediadores do espaço, nossos sujeitos de pesquisa}

A ECF é um dos espaços científico-culturais vinculados à Secretária Municipal de Educação (SEME) que atendem diferentes tipos de público gratuitamente, sendo estes visitantes: turistas, munícipes, grupos de estudantes agendados e avulsos, dentre outros.

A ECF localiza-se a Rua Jose de Anchieta - Parque Moscoso, região central de
Vitória, em um prédio inaugurado em 1952 que foi adaptado para receber os ins-
trumentos que a compõem. O prédio, tombado pelo patrimônio histórico estadual
é um importante representante da arquitetura modernista dotado de salas amplas
e boa iluminação. No local - com $2000 \mathrm{~m}^{2}$ de área construída - há cinco amplas
salas de exposições temáticas permanentes, um mini auditório, uma galeria para
exposições temporárias, banheiros para visitantes, sala administrativa e cozinha.
Na área externa um jardim com árvores antigas e painéis em mosaico, obra do
artista Anísio Medeiros que também, foram restaurados (ZUCOLOTO et al., 2011,
p. 23-24).

No dia 26 de abril de 2000 a ECF entrou em funcionamento, sendo legalmente instituída em 24 de setembro de 2001 com a Lei Municipal № 5.397 que "Cria a Escola da Ciência - Física e a Escola da Ciência - Biologia/História” (VITÓRIA, 2001). O documento oficial traz em anexo o regimento interno das Escolas das Ciências, entretanto as mudanças na SEME fizeram com que alguns princípios fossem alterados com o passar dos anos. O documento atual que rege os Centros de Ciência, Educação e Cultura de Vitória é o Decreto 17.015 de 02 de maio de 2017, no qual se encontra as seguintes atribuições:

a) proporcionar a relação entre o conhecimento científico e as vivências do currículo vigente na Educação Infantil e Ensino Fundamental; b) exemplificar por meio de experimentos concretos e vivenciais a complexidade dos conhecimentos curriculares, correlacionando teoria/prática/conhecimento/vivência; c) assegurar que o conhecimento científico produzido e compartilhado nos Centros de Ciência, Educação e Cultura de Vitória proporcione enriquecimento curricular para estudantes e se torne significativo e relevante à comunidade; d) acompanhar, preservar e complementar o acervo referente às ciências; e) planejar o atendimento ao público em geral e a escolares com vistas à efetivação do pleno funcionamento dos Centros de Ciência, Educação e Cultura de Vitória; f) propiciar espaços abertos para realizações artístico culturais e científicas envolvendo comunidade local; g) difundir conhecimentos científicos e o interesse pelo estudo do meio em que vive, possibilitando ampliação do saber e visão de seu público; h) promover a alfabetização científica como instrumento de acesso de todos ao conhecimento produzido 
pela humanidade; i) fornecer subsídios técnicos e/ou informações às Gerências Administrativas/Pedagógicas da Secretaria de Educação e outras entidades afins; j) coordenar, executar e verificar as atividades administrativo-financeiras de acordo com a legislação em vigor; $\mathrm{k}$ ) manter intercâmbio com entidades científicas, visando a troca de experiências; l) desenvolver capacidades de observação, evidenciando a amplitude e complexidade do conhecimento científico e sua relação com vida social; $m$ ) executar outras atividades correlatas ou que lhe venham a ser atribuídas (VITÓRIA, 2017, p. 6-7).

Podemos observar tanto atribuições que dizem respeito aos modos de funcionamento do espaço, tal como aparecem nos itens i) e j), quanto características voltadas para as ações educacionais para a sociedade de uma maneira geral, como em $\mathrm{h}$ ) e l), quanto ações mais articuladas ao currículo formal das instituições escolares vistas em a), b) e c)

A dimensão da ampliação da cultura e da educação pelo e para o patrimônio, tão cara aos museus, deve ser contemplada e as oportunidades de interação entre esses espaços devem levar à percepção de que os museus são mais do que complementos da escola, pois possuem uma identidade própria (MARANDINO, 2001, p. 97).

Quando consideramos o documento oficial e o que entendemos por escolas e museus, perpassando a interlocução com Marandino (2001), podemos perceber claramente que a ECF não é uma escola em si, mas sim um centro de ciências.

Sobre os sujeitos da pesquisa, é importante ressaltar que os nomes utilizados são fictícios, de modo a garantir o sigilo dos participantes da pesquisa. No quadro a seguir (Quadro 1), apresentamos os sete integrantes que participaram das rodas de conversa que constituíram a produção de dados da pesquisa e que são (ou foram) mediadores na ECF durante o desenvolvimento deste trabalho. Estão contempladas de igual modo as variáveis idade, características pessoais e de tempo de atuação que auxiliam na contextualização dos sujeitos e de suas narrativas. Todos os participantes da pesquisa eram estudantes de licenciatura em física no IFES - Campus Cariacica. 
Quadro 1: Caracterização dos mediadores

\begin{tabular}{|c|c|c|c|}
\hline Nome $^{2}$ & Idade & Características pessoais & $\begin{array}{l}\text { Tempo de atuação na ECF } \\
\text { (até setembro de 2017) }\end{array}$ \\
\hline Cleobulo & 20 & $\begin{array}{l}\text { Tem interesse em leituras, estudos e } \\
\text { gosta de jogar vídeo game }\end{array}$ & Iniciou as atividades em abril de 2017 \\
\hline Pítaco & 22 & $\begin{array}{l}\text { É guitarrista, professor de música e dá } \\
\text { aulas particulares de física }\end{array}$ & $\begin{array}{l}\text { Foi mediador durante um ano, saiu para se } \\
\text { dedicar a dar aulas de música. }\end{array}$ \\
\hline Bias & 21 & $\begin{array}{l}\text { Gosta de correr e está aprendendo a } \\
\text { tocar violino }\end{array}$ & Está como mediador a um ano e meio. \\
\hline Sólon & 18 & $\begin{array}{l}\text { Nas horas vagas gosta de jogar vídeo } \\
\text { game e montar cubo mágico }\end{array}$ & É mediador desde abril de 2017 \\
\hline Tales & 22 & $\begin{array}{l}\text { Gosta de pedalar, andar, fazer trilhas e } \\
\text { escalar }\end{array}$ & $\begin{array}{l}\text { Atuou durante três anos e durante a pesquisa } \\
\text { conseguiu um emprego }\end{array}$ \\
\hline Míson & 18 & $\begin{array}{l}\text { Ficção científica e super-heróis são algu- } \\
\text { mas de suas preferências }\end{array}$ & Atua desde junho de 2017 como mediador \\
\hline Quílon & 24 & Tem apreço por livros, animes e mangás & Participa das atividades desde agosto de 2017 \\
\hline
\end{tabular}

Uma característica comum a todos os mediadores que atuantes na ECF no período da pesquisa é que eles pertencem ao gênero masculino. Contudo, mediadoras já fizeram parte da equipe da ECF - este dado foi possível de constatar observando o livro de ponto em meses anteriores e a partir de relatos e conversas ao longo do tempo em que o autor participante do estudo de casa esteve no espaço. Ao olharmos para o estudo realizado por Carlétti (2016) sobre os perfis de mediadores e mediadoras científico-culturais que atuam no Brasil, mostrou dados distintos aos deste trabalho ao observar que discrepância 56,2\% dos sujeitos do estudo eram mulheres e 43,8\% homens.

Outra característica dos mediadores da ECF é a faixa etária, sendo que todos eles têm idade entre 18 e 25 anos. Carlétti (2016), em seu estudo a nível nacional, observou que $63,8 \%$ dos mediadores estavam na faixa etária entre 18 e 25 anos, característica compreensível ao lembrarmos que os mediadores na ECF são estudantes de graduação, enquanto o panorama nacional trazido por Carlétti (2016) leva em consideração espaços em que os mediadores são estudantes da educação básica e locais onde a mediação é consolidada como profissão, tendo sujeitos com mais de quinze anos de atuação.

\section{Análise e reflexões com os diálogos produzidos}

As análises dos dados produzidos durante as rodas de conversa possibilitaram categorizar as falas dos sujeitos ${ }^{3}$ a partir da leitura, análise e categorização das 
narrativas; assim, os processos formativos foram agrupados nos seguintes núcleos temáticos emergidos do estudo: (i) saberes vivenciais ou sobre o que se aprende ao longo da vida; (ii) saberes da formação escolar anterior ou o que se aprende com tantos professores; (iii) saberes didáticos ou os primeiros passos para a docência; (iv) saberes específicos ou sobre como se formam os cientistas; (v) saberes curriculares ou o que o local espera de nós enquanto educadores ; (vi) saberes experienciais ou sobre a alegria de estar sempre em construção.

\section{Processos formativos: fonte dos saberes necessários para a mediação}

Para atuar aqui na Escola da Ciência - Física, o que é que vocês acham que foi necessário aprender, o que vocês acham que, durante suas práticas quando vêm os grupos de visitantes, o que vocês utilizam para poder fazer a mediação? (Pesquisador)

A partir dessa questão, deram-se início as conversas em roda. De maneira geral, podemos "definir o saber docente como um saber plural, formado pelo amálgama, mais ou menos coerente, de saberes oriundos da formação profissional e de saberes disciplinares, curriculares e experienciais" (TARDIF, 2002, p. 36), e assim também podemos definir os saberes da mediação como um conjunto de conhecimentos que introjetados na prática de mediadores se torna fundamental para qualidade da mediação.

Qualquer um que tenha entrado em um espaço científico-cultural pode se remeter, a partir da fala de um mediador, a um momento de sua vida que lhe foi marcante, um episódio que lhe chamou a atenção e que não obteve resposta.

É legal que as pessoas ficam "é tão simples, mas tão genial”, mas é exatamente isso (Sólon)

Na ECF não é diferente, os encontros remetem a surpresa, a alegria e a diversão, direcionados por meio de ideias a partir de diferentes perspectivas dos mediadores. Para uma mediação crítica e problematizadora, que desperte o interesse do visitante, é necessário que o educador ou a educadora possua saberes próprios que potencialize as dimensões relacionais, lúdicas e afetivas.

[...] qual o papel do mediador? É realmente explicar o experimento? (Míson)

Na minha visão além de explicar é instigar a procura pelo conhecimento da pessoa... (Quílon) 
Exatamente... Entreter, porque se a pessoa viesse aqui pra aprender sobre como cada experimento funciona não precisaria de mediador... Só a placa já dava conta e era só colocar um segurança pra não quebrarem as coisas e pronto... (Míson)

E aí nem precisaria do experimento, era só ter escrito... E viraria um livro... (Quílon)

Aí eu volto a dizer... O pesquisador/ desculpa, o mediador ele tem esse papel de entreter a pessoa... (Míson)

Esse momento da conversa em que se envolvem Míson e Quílon aponta para uma reflexão sobre ser mediador. Reflexão crítica que deve perpassar toda a vida enquanto educador (FREIRE, 2011), seja em um centro de ciência ou em uma escola. A conversa entre Míson e Quílon aponta também para a importância dos mediadores no processo de produção de conhecimento nos espaços socioculturais, transpondo o conhecimento científico bruto em questões para os visitantes descobrirem as belezas das ciências.

\section{(i) Saberes vivenciais ou sobre o que aprendemos ao longo da vida}

Aqui estamos nós. Nós e a profissão. E as opções que cada um de nós tem de se fazer como professor, as quais cruzam a nossa maneira de ser com a nossa maneira de ensinar. É impossível separar o eu profissional do eu pessoal (NÓVOA, 2000, p. 17).

Não há como dissociar as atividades pessoais e profissionais de um educador compromissado com a formação crítica, dessa forma podemos dizer que todas as experiências vividas influenciam nos modos de ser mediador. Essa interação da história de vida com a profissão é notada na fala de um dos mediadores:

[...] no meu caso desde novo, desde os meus 12 ou 13 anos eu já tenho que lidar com pessoas, lidar com crianças por causa dos trabalhos/ de alguns bicos que eu fiz... Então a parte de lidar com o público, a parte de falar não era tanto o problema (Quílon)

A fala de Quílon contrasta com a de educadores que estão iniciando sua interação com os educandos, pois é comum apresentar certa timidez, medo ou vergonha ao iniciar a trajetória profissional enquanto educador, porém neste caso isso não foi demonstrado, uma vez que a barreira existente no primeiro contato já havia sido quebrada anteriormente na vida do mediador.

A esses saberes, construídos ao longo da vida do educador, podemos atribuir aos processos da educação informal, uma vez que, segundo Gohn (2006, p. 29): 
na educação informal, os agentes educadores são os pais, a família em geral, os amigos, os vizinhos, colegas de escola, a igreja paroquial, os meios de comunicação de massa, etc." e os locais onde ocorrem são "demarcados por referências de nacionalidade, localidade, idade, sexo, religião, etnia etc. A casa onde se mora, a rua, o bairro, o condomínio, o clube que se frequenta, a igreja ou o local de culto a que se vincula sua crença religiosa, o local onde se nasceu.

Ao contextualizarmos as obras de Gohn (2006), podemos dizer que na atualidade um forte componente da educação informal está no domínio da internet. Sólon aponta para esta influência pessoal quando começou a mediar na ECF:

Eu percebi que eu tive um referencial muito grande mesmo com professores ou até a galera do youtube que fazem uma parada bem diferente da gente... No meu primeiro mês a minha apresentação era uma mistura do Iberê do Manual do Mundo com o Átila do Nerdologia. Eu começava a apresentação falando "hoje nós vamos..." era ridículo. Hoje em dia eu já tenho uma/ eu já sinto que eu tenho uma forma de apresentar pessoal (Sólon) ${ }^{4}$

Sólon nos mostra que a internet como meio de comunicação molda ações na sociedade atual, entretanto a maneira como Sólon permite que este meio influencie suas ações dá indícios da importância da conscientização sobre seus usos.

Notamos a transformação das novas gerações. Sua comunicação, maneira de interagir, modos de brincar, entre outros aspectos, são alguns indicativos de que não só a sociedade está em constante mudança, mas também os educadores, por serem parte da sociedade e almejarem a democratização do conhecimento, devem transformar as práticas educacionais. A internet e as redes sociais são instrumentos que possibilitam essa articulação, não podendo ser negligenciadas como influentes na subjetividade de qualquer educando.

Todos os dias novos vídeos surgem com piadas prontas, conhecidas nas redes sociais como memes. Esses memes integram o discurso atual, sendo praticado muitas vezes como uma linguagem paralela presente na oratória cotidiana. Pítaco utiliza dessa artimanha para trazer os visitantes para conversa no momento das visitas. Ele nos conta que a partir de como o grupo se comporta, é possível inserir elementos dessa nova linguagem de modo que os visitantes o aceitem como um elemento do grupo e fique mais fácil encaminhar a visita. Durante a visita, Píton tenta perceber

[...] o que que a galera gosta de falar, o que a galera gosta de ouvir... Aí você falando o que eles gostam de ouvir sei lá piada, meme de internet, diversão [...] você se divertir com eles e acaba que eles vêm junto com você (Pítaco) 
Muitos são os saberes pessoais que se enraízam nas práticas dos mediadores da ECF.

\section{(ii) Saberes da formação escolar anterior ou o que aprendemos com tantos}

Será que esses trocentos professores que a gente já teve interferem em nossa maneira de dar aula? Ou... se será que o certo mesmo é o aluno se espelhar neles? Ou será que se eu for pegar por exemplo me debruçar numa pesquisa seja ela numa literatura numa coisa escrita ou então vídeos eu vou encontrar pessoas que falam sobre aquilo ou sobre como poderiam ser, entendeu? (Pesquisador)

Antes de cogitar ser educador em um centro de ciência, qualquer indivíduo que pretenda ser mediador já possui em seu histórico estudantil mais de dez mil horas em sala de aula como estudante da educação básica, tempo suficiente para elaboração "de crenças, de representações e de certezas sobre a prática docente" (TARDIF, 2002, p. 261). É fácil recordar daquelas professoras/professores que nos marcaram por sua dedicação à profissão, sua amorosidade ao ensinar e o zelo pela formação de seus alunos como cidadãos. Por outro lado, a lembrança daquelas professoras/ professores que não se preocupavam com a aprendizagem, apenas copiava textos no quadro e puniam como forma de avaliação também fica evidente na memória. Outros exemplos poderiam ser apontados como processos formativos para um educador antes mesmo que se identifique como tal, e "percebe-se que a maioria dos dispositivos de formação inicial dos professores não conseguem mudá-los nem abalá-los. Os alunos passam pelos cursos de formação de professores sem modificar suas crenças anteriores sobre o ensino" (TARDIF, 2002, p. 261).

A gente já teve professores então a gente meio que já tem muitos moldes [...] o que quis dizer sobre usar um professor como molde é basicamente "esse cara dá uma aula boa gostei do jeito dele" ou "esse cara dá uma aula ..., não posso fazer como ele", tá ligado (Pítaco)

Pítaco apresenta a influência exercida por professores que ele teve ao longo de sua vida. Como seres inacabados, a formação acontece continuamente na vida do educador, porém cabe refletir sobre o que carregar como elemento da cultura docente nos encontros que ocorrem nas salas de aula. 
Em algumas oportunidades ao interagir com os mediadores da ECF, o assunto em foco era sobre o papel do professor na visita à ECF, uma vez que o comportamento da turma, a maneira como a visita se desenvolve, as interações promovidas e os diálogos são parcialmente potencializados pela participação do "responsável” pela turma. Falávamos sobre a postura do professor ou da professora desde o momento em que eles entram em contato com a ECF para agendar a visita, pois entendemos que, se uma professora/professor pretende que seus educandos/educandas aprendam algo em específico, ou seja, algum conteúdo relacionado a matéria que estão estudando, é necessário que os professores comuniquem com antecedência a fim de os mediadores possam se preparar de modo a atender a esse objetivo. Tales é categórico neste sentido ao afirmar que "eu acho até certo quando o professor quer dar/ ele pode falar com você "ah, eu quero que você de ênfase em tal área" aí o que que você faz? Quando tiver naquela parte você dá ênfase se for possível”. Continuando a conversa com a literatura:

\begin{abstract}
Vamos supor, por exemplo, que o professor pense que uma visita guiada seja uma boa ideia. Nesse caso, a situação ideal seria que o professor orientasse a visita, tendo os 'explicadores' como auxiliares. Na verdade, esse é um tipo muito raro de visita. Dificilmente há tempo para preparar com antecedência uma boa visita escolar, pois isso demandaria muito tempo e esforço de parte dos professores (GOMES DA COSTA, 2007, p. 31).
\end{abstract}

Ao trazer a problematização quanto à postura docente relativa ao agendamento da visita, pretendíamos que os mediadores pensassem a longo prazo quando estivessem como docentes atuantes em uma escola e pensassem em levar seus educandos em um espaço científico-cultural. Como eles fariam para que a visita fosse mais proveitosa? Eles iriam fazer como os professores que agendam e em cima da hora solicitam algo em específico? Iriam deixar os estudantes sob a responsabilidade dos mediadores enquanto se distraíssem com qualquer outra coisa? Essas e outras questões devem ser refletidas antes de uma resposta trivial, haja vista as variáveis que estão em jogo. $\mathrm{O}$ fato é que a maneira como os professores agem implica em como os mediadores vão atuar futuramente.

Ao se colocar na posição do professor ou professora, seria importante que o sujeito possuísse o que Queiróz e colaboradoras (2002, p. 86) chamam de saber da concepção da exposição, em que se acentua a necessidade de conhecer as "ideias das pessoas que idealizaram, planejaram e executaram a exposição, o que inclui o saber da tendência pedagógica da exposição”. Acreditamos que só assim o professor 
poderia alcançar seus objetivos pessoais e educacionais ao levar o grupo de estudantes a um centro de ciência.

\section{(iii) Saberes didáticos ou os primeiros passos para a docência}

Durante uma das rodas de conversa, ao se discutir sobre os professores que cada um já teve, Tales comentou sobre um professor da disciplina de diversidade e processos inclusivos e a questão da deficiência:

[...] ele falava uma coisa que era interessante "não é a pessoa que é deficiente, é o prédio que é deficiente" porque o cadeirante nasceu antes daqueles prédios subirem, então se ele não tem acesso pro cadeirante quem é deficiente é aquele prédio, porque ele veio depois e aí você começa a olhar pra socie/ começa a olhar pro mundo assim... "Pô, o cadeirante não passa aqui. Essa escola aqui tem um banheiro ali de cadeirante" beleza, mas como que o cadeirante sai daqui e vai pra área externa se não tem nenhuma rampa que dá acesso a ele? Você já começa a olhar assim "como que ele vai fazer isso? Como que ele vai fazer aquilo?" você já se adapta a sua visão daquilo que tá fazendo praquilo que a gente viu (Tales)

Tales aponta para uma reflexão que surgiu durante sua formação pedagógica e que fora transportada para a ECF. Mediante essa demanda, é necessário reavaliar a conexão (QUEIRÓZ et al., 2002) entre os equipamentos do local, é importante que o mediador conheça o espaço para que não prive nenhum visitante das interações objetivadas pelo museu.

Outra influência que pode ser associada à formação docente está presente na narrativa de Sólon, referente à necessidade de se explicar os conceitos relacionados aos objetos culturais, mesmo que em outros momentos os mesmos sujeitos tenham apresentado uma visão diferente.

Eu vejo muito como etapas... Por exemplo, pra você explicar elétrica você tem que explicar o que é um átomo, e ter que explicar de onde vem o elétron numa turma de criança é mais difícil [por]que você não pode chegar nem na primeira etapa, tu tem que se divertir sem falar nada... Tu pode até deixar uma dúvida ou outras na criança, mas tu não tem que explicar nada e isso é uma parada que é bem difícil, porque eu quero explicar as paradas pra criança e eu sei que ela não vão entender (Sólon)

“Ter que explicar" está presente no discurso dos mediadores de uma forma que é difícil de ser desvinculada. Na primeira roda de conversa, a qual teve duração de pouco mais de duas horas, foram mencionadas vinte e cinco vezes a palavra "explicar" por parte dos mediadores, já a palavra “dialogar” não foi referida nenhuma vez 
e o termo "conversar" apenas uma vez, entretanto, o contexto em que esta última apareceu não era o de conversar propriamente com o público.

Torno a fazer a pergunta que dá nome ao artigo de Gomes da Costa (2007) “os 'explicadores' devem explicar?”, artigo que, inclusive, foi disponibilizado para os mediadores da ECF enquanto o primeiro autor dessa pesquisa atuava no espaço a fim de que problematizassem os processos de formalização necessários para o atendimento no museu.

A questão é saber o que eles sabem e como sabem, e aprender a ensinar-lhes coisas que elas ainda não sabem mas querem saber. A questão é saber se meu conhecimento é necessário porque às vezes não o é. Outras vezes é necessário, mas essa necessidade ainda não foi percebida pelas pessoas. Então, uma das tarefas do educador e educadora é também provocar a descoberta de necessidade de saber e nunca impor um conhecimento cuja necessidade ainda não foi percebida (FREIRE; HORTON, 2003, p. 86).

Por que não dialogar, levando em consideração os saberes trazidos pelos visitantes em vez de levar a eles uma base pronta? Uma questão que só pode ser respondida pela via das transformações no ser educador.

\section{(iv) Saberes especificos ou sobre como se formam os conceitos cientificos}

Conhecer o conteúdo que está posto em diálogo é caráter fundamental para qualquer educador, seja ele na escola ou no centro de ciências. O saber da formação específica se envolve cotidianamente nas vozes de mediadores culturais. Freire (2003) nos fala que para ensinar, existe o compromisso anterior de saber o que se vai ensinar, mesmo que durante o processo se aprenda mais, e se deve aprender mais a cada vez que uma pessoa diferente lhe faz uma pergunta ou você lança uma questão a ela. A esse respeito, Cleobulo comenta sobre seus saberes específicos a respeito dos fenômenos das ciências físicas.

Os conhecimentos de ciências eu já tinha porque eu estudava física também, sempre gostei de física, de pesquisar ciência, mas na hora de falar, de desenvolver ali pra uma turma já era diferente, eu já não sabia fazer direito (Cleobulo)

É perceptível a confiança que depositam no conhecimento científico, entretanto sabemos que, enquanto sujeitos educadores, devemos estar conscientes de nossa incompletude; dessa forma, devemos buscar sempre novos modos de interpretar o mundo (FREIRE, 2011). 
A princípio, os fenômenos relacionados aos objetos da ECF são de simples compreensão, não necessitando de um aprofundamento conceitual para dialogar com o público em geral, porém a diversidade social nos surpreende a todo instante, surgindo perguntas desafiadoras. Pensando em uma mediação problematizadora, a postura do mediador não deveria ser o de dar a resposta, mas estimular o visitante a responder a sua própria pergunta. "O papel do educador progressista é desafiar a curiosidade ingênua do educando para, com ele, partejar a criticidade. É assim que a prática educativa se afirma como desocultadora de verdades escondidas" (FREIRE, 2006, p. 79).

Outro momento da roda de conversa que destacamos foi quando Sólon, em dois momentos distintos, apresentou sua visão quanto aos conhecimentos científicos na ECF:

Algumas coisas, tipo o empuxo, eu tava com um pouco de dificuldade pra explicar e aí depois que eu tive aula com o [professor] melhorou muito (Sólon)

Eu acho que na real, daqui o que eu menos aprendi foi conceito científico, foi mais como se relacionar com as pessoas que chegaram aqui e que eu acabei de conhecer (Sólon)

E essa dimensão que Sólon traz é importante, uma vez que é fundamental que mediadores em centros de ciências saibam conversar com o público. Uma vez conhecida a ECF, sabemos que a formação curricular realizada a partir da leitura do "Roteiro do Acervo: Pasta de Estudos dos Estagiários" (sobre essa pasta, ler a seção seguinte) se confunde com as formações específicas. É comum que o mediador ignore as horas em sala de aula de sua formação acadêmica quando eles estão conversando em roda e valorizando outros aspectos de sua formação, porém os textos em si trazem para o diálogo interno os fenômenos e conceitos aprendidos.

\section{(v) Saberes curriculares ou o que o local espera de nós enquanto educadores}

A mediação estabelecida na ECF é bastante direcionada a partir das instruções passadas pelo responsável pedagógico - René ${ }^{6}$. Tradicionalmente, René orienta os novos mediadores para suas ações e, sempre que solicitado, ele explica como funcionam os experimentos, como atender os diferentes públicos, como resolver conflitos que o mediador esteja passando. 
Ao conversar com os mediadores e com o René, ele disse: "Qualquer dúvida é para vir e perguntar, tirar as dúvidas nessas primeiras semanas”, incentivando os mediadores a procurá-lo. As palavras utilizadas por René ecoam nos discursos dos mediadores quando o assunto é o objetivo da ECF. Um exemplo é trazido por Míson, quando ele diz:

O René que foi quem nos deu essa formação sempre nos diz e eu concordo com ele "se a pessoa vir aqui e não aprender uma vírgula sobre física, mas sair curiosa e tendo interesse, o papel foi feito" (Míson)

O caráter curricular (TARDIF, 2002) da formação dos mediadores se mostra em vias de uma formação que "abra a mente dos visitantes", de modo que esses sejam os sujeitos participantes na mediação. A ideia da curiosidade como fator preponderante nos visitantes é essencial para a satisfação dos mediadores em um museu de ciência.

Como mencionado por Míson anteriormente, o René provoca os estudantes para que a visita seja prazerosa e desperte o interesse nos visitantes, porém, mesmo estando disponíveis aos mediadores, nem sempre eles o procuram para sanar seus conflitos. Alguns sentimentos por parte dos mediadores estão atravessados nessa dificuldade de comunicação, o que repercute em sua formação curricular inicial na ECF.

No início foi meio difícil pra mim, eu fiquei meio perdido, não sabia se eu lia o roteiro, se eu via as apresentações, se eu pesquisava na internet, fiquei meio perdido (Míson)

Eu fiz exatamente isso pesquisar na internet, ver os monitores antigos e ler o roteiro (Sólon)

Percebemos de igual modo que os mediadores se sentem mais à vontade para explorar e conversar com seus colegas, o que nos levou a enxergar a concepção da formação a partir das experiências de mediadores com mais tempo em serviço.

Refletindo sobre os modelos propostos por Marandino (2008), surge a dúvida se esse modelo de formação estaria mais parecido com outro modelo centrado na (auto) formação ou na relação aprendiz-mestre. Não é intenção colocar os mediadores da ECF em uma categoria fechada, mas apenas pensar as relações possíveis em um centro de ciência e compreender como esta ocorre. A própria autora (MARANDINO, 2008, p. 27) sinaliza para o fato de que "tais modelos não são excludentes e que muitas vezes são utilizados de forma concomitante pela instituição formadora”, o que é o caso da ECF. 
Acima podem ser observadas as falas de dois mediadores, entretanto cada sujeito ao narrar sua trajetória evidencia algum ponto novo, diferente dos demais. A história de Tales é um pouco diferente, por ter começado a atuar na ECF antes dos demais e num cenário que era outro.

Quando eu cheguei aqui foi chegar aqui no meio de ninguém que faz física, todo mundo era biólogo, todos os estagiários eram biólogos e isso foi a melhor coisa que já aconteceu. (Tales)

Quando Tales começou na ECF os mediadores eram conhecidos como estagiários, pois o contrato era realizado diretamente com a Prefeitura Municipal de Vitória, compondo o quadro de mediadores e mediadoras estudantes interessados em atuar independente da formação ou instituição de origem. O diálogo entre as múltiplas formações é uma aposta que colabora na construção de um espaço com olhares diversos focados num mesmo objeto cultural e é referente a este ponto que Tales teceu seu comentário e deixou claro durante a roda de conversa, ou seja, que esses encontros foram potentes no sentido da aprendizagem, de se colocar como educador frente a outras visões de mundo.

Aqui, percebemos que o representante da instituição sugere o diálogo, a troca de conhecimentos e se apresenta como suporte para quaisquer eventuais dificuldades que os mediadores possam apresentar, possibilitando uma maior apropriação do conhecimento sobre o local e sobre o que se propõe a oferecer para seus públicos.

Em primeiro lugar eu quero que eles se divirtam... Se ele veio aqui e não aprendeu nada mas ele se divertiu, pra mim já tá valendo, porque ele saiu com a diversão e ele vai eternizar na memória dele aquilo que ele vivenciou aqui (Tales)

Nosso maior desafio aqui é levar isso ao público e fazer com que eles gostem realmente que não fique algo maçante e eles realmente se sintam atraídos por essa área da ciência (Bias)

Tales e Bias concordam com o objetivo do espaço como é proposto pelo responsável e pela legislação vigente.

g) difundir conhecimentos científicos e o interesse pelo estudo do meio em que vive, possibilitando ampliação do saber e visão de seu público; [...]

1) desenvolver capacidades de observação, evidenciando a amplitude e complexidade do conhecimento científico e sua relação com vida social (VITÓRIA, 2017, p. 6-7).

Em outras palavras, a formação proporcionada pela equipe pedagógica da ECF atende as demandas municipais, justificando a consolidação do espaço frente à 
sociedade. Além disso, proporciona aos mediadores a percepção de diferentes experiências durante sua atuação no centro de ciência.

\section{(vi) Saberes experienciais ou sobre a alegria de estar sempre em construção}

Conforme foi passando o tempo eu fui observando os outros monitores explicarem os experimentos e fui aprendendo mais com a explicação deles mesmo né, mais do que com os conhecimentos de fora (Cleobulo)

O modelo centrado na relação aprendiz-mestre ou na prática (MARANDINO, 2008) é muito comum na formação de mediadores em museus de ciências, sendo considerada a principal maneira pela qual os mediadores e mediadoras adquirirem os saberes necessários para a sua mediação. Gomes (2013) discute sobre essa formação em sua pesquisa e problematiza os motivos que levam à supervalorização da prática.

Vale questionar se esta valorização da formação em serviço se deve a uma escolha dos profissionais envolvidos na formação de mediadores, ou se é influenciada por limitações de tempo, orçamentárias ou outras, que impediriam a realização de ações de formação inicial com maior duração (GOMES, 2013, p. 121).

Durante uma das rodas de conversa foi tensionado o fenômeno da rotatividade dos mediadores, colocando em questão se o motivo da ênfase na formação a partir da prática não se dá por falta de um corpo profissional sólido, dificultando o empenho da equipe pedagógica em organizar formações para todos.

A ideia de que os saberes da experiência bastam para que se possa mediar o conhecimento presente no acervo da ECF é abordado em um trecho da narrativa de Bias.

Com relação à formação para atuar aqui... Eu não acho que seja algo realmente necessário porque pelo que eu vi os bolsistas da Prefeitura também não tiveram uma formação, eles foram pegando com o tempo e desenvolveram técnicas próprias... Então com o tempo aqui, com a presença de outros bolsistas, você vai aprendendo coisas e vai se desenvolvendo (Bias)

A concepção de formação presente na narrativa de Bias se reduz à condição de um curso específico, uma vez que este era o contexto específico no momento da conversa. Porém, é curioso observar que essa percepção se sustenta na formação aprendiz-mestre (MARANDINO, 2008). Consideramos que os saberes da experiência são fundamentais além de serem fonte de conhecimento indispensável para qualquer educador. Inclusive, é um dos pontos que mais se destacaram ao longo das rodas 
de conversa, porém há que se reconhecer que a formação em serviço só é possível quando se tem um conhecimento prévio sobre o tema que está sendo tratado, com um olhar do ponto de vista de uma formação crítica e consciente de cada educador (FREIRE; HORTON, 2003). Dessa forma, é possível uma potente formação na e com a prática.

São os encontros com os indivíduos mais experientes que proporcionam reflexões ímpares no contexto da profissão de educador e de seu desenvolvimento profissional (NÓVOA, 2009). Esses encontros potencializam a aprendizagem e ajudam a consolidar o perfil profissional de cada um. Entretanto, Freire (2011) sinaliza que a prática por ela mesma, sem articulação com a teoria, corre o risco de se tornar puro ativismo, ação sem pensamento, sem reflexão, enquanto o oposto também não é aconselhável. Teoria que não é colocada em prática se torna mero blá-blá-blá. Dessa forma, é importante entender que "na concepção de Freire, teoria e prática são inseparáveis tornando-se, por meio de sua relação, práxis autêntica, que possibilita aos sujeitos reflexão sobre a ação, proporcionando educação para a liberdade" (FORTUNA, 2015, p. 65). É organizando os conhecimentos teóricos junto aos desdobramentos das visitas que os saberes da experiência tendem a se constituir, a tornarem-se parte do discurso, na inter-relação entre teoria e prática, na práxis autêntica dos educadores e educadoras nos museus/centros de ciências.

É preciso que fique claro que, por isto mesmo que estamos defendendo a práxis, a teoria do fazer, não estamos propondo nenhuma dicotomia de que resultasse que este fazer se dividisse em uma etapa de reflexão e outra, distante, de ação. Ação e reflexão se dão simultaneamente (FREIRE, 1988, p. 125).

Na transformação reflexiva, as experiências dos mediadores foram desvendando caminhos, como o que Cleobulo apresenta:

[...] e sobre o que você falou de que aqui é um espaço de curiosidade é uma coisa que eu tô aprendendo ainda, e essa semana foi muito importante pra mim porque eu comecei a pegar umas turmas né, de menininhos pequenininhos... Eu peguei uma de meninos de três e quatro anos e eu não soube como agir tive que pedir auxílio para o Sólon porque eu não sabia o que fazer direito (Cleobulo)

A dúvida gerada na ação, o convite ao diálogo e reflexão com outro mediador e a nova ação se dão num mesmo momento, da práxis libertadora, "o seu quefazer, ação e reflexão, não pode dar-se sem a ação e a reflexão dos outros, se seu compromisso é o da libertação" (FREIRE, 1988, p. 122). 
Entendemos que os saberes da experiência também se dão na colegialidade, nas trocas de conhecimentos e na interação dialógica. As narrativas dos mediadores se encontram diversas vezes nesse ponto, isto é, no ponto em que sua formação é complementada mediante apresentação de um problema para um colega e juntos buscam uma solução. Concordando com Moita (2000), os mediadores da ECF apresentam um fator que reflete uma experiência coletiva de parceria na profissão.

Ninguém se forma no vazio. Formar-se supõe troca, experiência, interações sociais, aprendizagens, um sem fim de relações. Ter acesso ao modo como cada pessoa se forma é ter em conta a singularidade da sua história e sobretudo o modo singular como age, reage e interage com os seus contextos. Um percurso de vida é assim um percurso de formação, no sentido em que é um processo de formação (MOITA, 2000, p. 115).

Além da formação com os pares, existem diversos encontros que compreendemos como processos formativos. Raros são os momentos em que o mediador se encontra sozinho devida a constante movimentação de visitantes nos museus, o que se configura como tempo e espaço suficientes para a criação de certos hábitos.

Na narrativa de Cleobulo, notamos sua preocupação acerca de diferentes aspectos da visita para os visitantes. Quando ele diz que não sabe como agir, deixa claro que encontra dificuldades em conversar, interagir, divertir, ensinar os meninos - como ele os denomina. "Vale a pena também destacar que, ao visitar o museu, busca-se uma experiência prazerosa e divertida, mas também de ensino e de aprendizagem" (MARANDINO, 2008, p. 25). Sob a visão apontada por Marandino (2008), Cleobulo se desdobra para encantar e ensinar um pouco de ciências para as crianças, mas essa é uma tarefa bastante complexa, tendo em vista que o mediador se encontra no início de uma formação acadêmica, e que mesmo que estivesse nos anos finais, essa não ainda contemplaria a formação para atuação na educação infantil, somente para alguns casos no Ensino Fundamental.

Outra vez os saberes da experiência são construídos pela via da aproximação entre pares. Tales apresenta sua experiência ao referir que:

O cara tá passando uma teoria sobre aquele experimento... Mas olhando pra ele agora, pega em volta e olha pra cara de cada um que tá olhando pra ele como eles estão se sentindo? Eles tão ali olhando... Tão quieto? Tão brincando? Eu acho que/ que aí com esse convívio com a biologia, eu vi que não tem que se aprofundar em tudo, não tem que mostrar/ tem que fazer com que eles se divirtam (Tales) 
Apesar de parecer um pouco confuso, a narrativa de Tales diz respeito à percepção enquanto mediador sobre o envolvimento do público em uma visita. Essa percepção tem a ver com a sensibilização frente ao outro, a empatia durante a mediação. Para ele, essa característica foi apreendida no contato com os mediadores e mediadoras da ECF, que eram estudantes de ciências biológicas. Segundo Tales, diferentemente dos estudantes de física, os de ciências biológicas teriam uma facilidade maior em colocar-se no lugar do outro. A percepção apontada por Tales é um ponto que Brito (2008) chama à reflexão.

A opção por alunos da graduação das muitas áreas do conhecimento traz diversos olhares para o tema tratado. O aprendizado dos futuros mediadores ocorre em uma perspectiva multidisciplinar, proporciona a troca de experiências, contribui para a sua formação pessoal, profissional e acadêmica e reduz o discurso especializado e técnico, flexibilizando, assim, o atendimento ao público (BRITO, 2008, p. 41).

Entretanto, no contexto desta pesquisa, poucos foram os mediadores que tiveram a oportunidade de trabalhar em meio a um corpo multidisciplinar de educadores.

Por meio dos conhecimentos construídos no e com o espaço consideramos que, durante o tempo de atuação na ECF, se desenvolve o sentimento de pertença e o de que aquele acervo também é um patrimônio cultural. Essa experiência contribui para a mediação, compondo saberes que Queiróz e colaboradoras (2002) denominaram como a grande categoria dos saberes mais propriamente de museus. Dentro dessa grande categoria existem conhecimentos relacionados à instituição em si, mas também sobre a história da humanidade e a concepção da exposição, saberes que moldam os mediadores e leva para cada um a percepção de que na totalidade ele é único.

A compreensão da ECF como espaço educativo auxilia na percepção dos mediadores de que, para que um indivíduo aprenda algo que ele quer ensinar, temos que dialogar com as múltiplas experiências e saberes, além disso, é preciso que o visitante se divirta e se interesse por saber mais - esse é um dos pressupostos da ECF, como já abordado anteriormente. A relação com o público, de articular um saber da transposição didática com a vida e a ciência é um ponto abordado por Cleobulo:

[...] e eu fui percebendo que esse espaço aqui é um espaço de ciência também né, que carrega esse nome da ciência - física e a gente explica um pouco de física aqui, mas aqui é mais um espaço de curiosidade mesmo onde a pessoa se surpreende com essa coisa diferente que tem que é a física né, e ela não se dá conta que existe na vida dela todos os dias toda hora (Cleobulo). 
Anteriormente, Cleobulo tinha apontado que suas experiências o fizeram perceber que a ECF é um espaço de curiosidade, e aqui ele percebe que também é um lugar de ciência. Esse saber vem de sua experiência com o uso diário da ciência e da tecnologia e que, portanto, é insumo-chave a ser explorado por meio de referenciais familiares que permitam ao visitante uma aproximação com o conceito trabalhado no museu/centro de ciência (AVELLANEDA et al., 2008, p. 34).

Cada passo que é dado faz parte da formação de si e do outro no museu, faz parte também da formação consciente de cada agente que produz e comunica o que sabe. No ato de comunicar, ou seja, de falar e ouvir, as experiências vão se constituindo, experiência marcante na vida de um mediador (LARROSA, 2002). Cada vez que, na práxis autêntica, um sujeito se coloca no lugar do outro, ele é formado para a liberdade.

\section{Considerações finais}

durante a produção desta pesquisa foi possível constatar que a reflexão sobre o processo formativo do mediador e da sua experiência com a divulgação científica podem auxiliar de igual forma os futuros pesquisadores a compreenderem os processos formativos que influenciam na constituição dos saberes e fazeres da mediação em um centro de ciência. Observamos que há muito mais na prática dos mediadores do que pode oferecer o ensino formal ofertado pela instituição de ensino de cada mediador, além de que, existem diversas esferas da vida que se constituem como redes que sustentam a forma como o conhecimento científico circula em um espaço característico da educação não formal.

Dentro dos processos formativos, os quais são fontes de saberes necessários para a mediação, encontramos nas narrativas dos mediadores as origens de seus saberes. Dentre elas, destacamos a influência que as mídias eletrônicas exercem, como apontado por Sólon, quando este lembra que ao começar na ECF tinha o costume de repetir jargões de youtubers e buscava nesses novos popularizadores da ciência fonte de inspiração para suas práticas. Outro ponto marcante é quando Tales relembra a reflexão conduzida por um de seus professores durante a formação acadêmica sobre deficiência física, a qual aponta que não se deve pensar nas pessoas como limitadas em termos de acesso ao espaço, mas sim que o espaço é deficiente 
em não proporcionar a chance de interação para todos, sabendo que a sociedade é extremamente diversificada em relação aos sujeitos que a constituem.

Entretanto, notamos a forte presença de uma formação pautada no modelo da autoformação (MARANDINO, 2008), no qual os mediadores devem buscar seus próprios meios para atuar. Em alguns momentos também ficou evidente a formação pela via da relação aprendiz-mestre, o que também parece surgir do descaso com a excelência no atendimento da instituição. Infelizmente, essa denúncia vem em um momento em que a população passa por um momento difícil na política nacional. Por outro lado, é reconfortante saber que a partir desse ponto é possível transformar o quadro vigente de modo a levar cada vez mais em consideração as particularidades e demandas dos mediadores em sua formação.

Por fim, considerando o momento pelo qual a Educação tem passado e as dificuldades que as políticas educacionais têm enfrentado, podemos concluir que a ECF tem atendido os seus objetivos enquanto instituição, porém ao se lutar por um futuro mais justo e melhor, é que apostamos em uma "educação problematizadora, que não é fixismo reacionário, é futuridade revolucionária” (FREIRE, 1988, p. 73). Acreditamos na utopia e na continuidade dos anúncios e das denúncias. "Reinsisto em não ser possível anúncio sem denúncia e ambos sem o ensaio de uma certa posição em face do que está ou vem sendo o ser humano" (FREIRE, 2000, p. 119).

\section{Formative processes and mediation in science centers and museums: the case of a science center in Vitória/ES}

\section{Abstract}

This study aims to understand the formative processes that impact on the constitution of one's knowledge and knowhow as mediators in a science center. This case study has as its subjects the mediators of a Science Center in Vitória-ES. The participation of this article's first author as a volunteer mediator contributed to the data collection process. As part of the data, as the transcriptions of the audios from two conversation circles conducted by the first author. The data were analyzed using Freire's framework in articulation with teaching knowledge and the mediation knowledge required in science centers. The interpretations highlighted the electronic media influence as a source of inspiration, as well as the schooling processes, especially regarding pedagogical knowledge. Another aspect highlighted, is the process self-training of mediators.

Keywords: Formative processes. Mediation knowledge. Science center 


\section{Notas}

1 Esta pesquisa compõe o projeto "Narrativas (auto)biográficas e reflexividade: contributos para a formação inicial e continuada de professores" com registro 44931315.4.0000.5542 no Comitê de Ética/Plataforma Brasil e com aprovação em 28/08/2015.

2 Os nomes escolhidos para os mediadores são os dos Sete Sábios, figuras escolhidas por Platão para exemplificar a eficácia da educação lacedemônia em Protágoras (343a).

3 As narrativas serão apresentadas ao longo do artigo da maneira como foram enunciadas pelos mediadores, assim sendo, poderemos verificar o uso da linguagem coloquial podendo conter o uso de gírias, dialetos e vícios de linguagem dos sujeitos.

4 É importante sinalizar que ao dizer "era ridículo", Sólon falava de uma maneira que era possível reconhecer a mudança e a criação de uma personalidade própria, expressa logo em seguida e não uma crítica aos canais do Youtube.

5 O termo explicador é uma tradução livre de explainers, que são mediadores na língua inglesa.

6 René (nome fictício) é professor de ciências na Prefeitura Municipal de Vitória e atua na coordenação pedagógica da ECF, instituição em que é alocado desde 2002. Na ECF o coordenador pedagógico oferece formação inicial para os mediadores, organiza as atividades de férias, dialoga com diferentes instâncias e secretarias de educação. René não havia sido mencionado enquanto sujeito da pesquisa, entretanto o caráter etnográfico, resultante da imersão do primeiro autor no campo estudado, imprime a participação de diferentes sujeitos na produção dos dados.

\section{Referências}

ABRAHÃO, M. H. M. B. Intencionalidade, reflexividade, experiência e identidade em pesquisa (auto)biográfica: dimensões epistemo-empíricas em narrativas de formação. In: BRAGANÇA, I. F.; ABRAHÃO, M.H.M.B.; FERREIRA, M. S.. (Org.). Perspectivas epistemo-metodológicas da pesquisa (auto)biográfica. Curitiba: CRV, v. 1, p. 29-50, 2016.

ANDRÉ, M. E. D. A. O que é um estudo de caso qualitativo em educação? Revista da FAEEBA - Educação e Contemporaneidade, Salvador, v. 22, n. 40, p. 95-103, jul./dez., 2013.

AVALLANEDA, M. F.; ROJAS, A. A.; FALLA, S.; HOYOS, N. E. Os guias em Maloka: dez anos de aprendizagem. In: MASSARANI, L. (org.) Workshop Sul Americano e Escola de Mediação em Museus e Centros de Ciências. Rio de Janeiro: Museu da Vida/Casa Oswaldo Cruz/ Fiocruz, p. 29-36, 2008.

BRITO, F. Experimentando a mediação: desafio constante. In: MASSARANI, L. (org.) Workshop Sul Americano e Escola de Mediação em Museus e Centros de Ciências. Rio de Janeiro: Museu da Vida/Casa Oswaldo Cruz/Fiocruz, p. 37-42, 2008.

CARLÉTTI, C. Mediadores de centros e museus de ciência brasileiros: quem são esses atores-chave na mediação entre a ciência e o público? 2016. 2010. 339 p. Tese (Doutorado em Ciências) - Instituto Oswaldo Cruz, Pós-Graduação em Ensino em Biociências e Saúde, Rio de Janeiro, 2016.

CARVALHO, A. V. Os saberes docentes nas visões de Paulo Freire e Maurice Tardif: uma contribuição. Revista Góndola, Enseñanza y Aprendizaje de las Ciencias, v. 9, n. 2, p. 34-43. 2014. 
CODES, A. L. M.; SILVA, F. A. B.; ARAÚJO, H. E. SIPS CULTURA Percepções e Cultura. In.: SCHIAVINATTO, F. Sistema de indicadores de percepção social (SIPS). 1ª Ed. - Brasília: Ipea, 2011.

COELHO, G. R.; BREDA, V. C.; BROTTO, T. R. A. Atividades em um centro de ciências: motivos estabelecidos por educadores, suas concepções e articulações com a escola. Educ. Pesqui., São Paulo, v. 42, n.1, p. 525-538, abr./jun., 2016.

CRESTANA, S.; HAMBURGER, E. W.; SILVA, D. M.; MASCARENHAS, S. (orgs.). Educação para a ciência: curso para treinamento em centros e museus de ciências. São Paulo: Editora da Física, 2001.

FORTUNA, V. A relação teoria e prática na educação em Freire. Revista Brasileira de Ensino Superior, v. 1, n. 2: 64-72, out./dez., 2015.

FREIRE, P. Conscientização: teoria e prática da libertação: uma introdução ao pensamento de Paulo Freire - São Paulo: Cortez \& Moraes, 1979.

FREIRE, P. Pedagogia do oprimido. Rio de Janeiro, RJ: Paz e Terra, 1988.

FREIRE, P. Professora sim, tia não! Cartas a quem ousa ensinar. São Paulo: Editora Olho d'Água, 1997.

FREIRE, P. Pedagogia da indignação: cartas pedagógicas e outros escritos. São Paulo: Editora UNESP, 2000.

FREIRE, P.; HORTON, M. O caminho se faz caminhando: conversas sobre educação e mudança social. Petrópolis, RJ: Vozes, 2003.

FREIRE, P. À sombra desta mangueira. 8ª Ed. São Paulo: Editora Olho d’Água, 2006.

FREIRE, P. Pedagogia da autonomia: saberes necessários à prática educativa. São Paulo: Paz e Terra, 2011.

GALVÃO, C. Narrativas em educação. Ciência \& Educação, v. 11, n. 2, p. 327-345, 2005.

GOHN, M. G. Educação não-formal, participação da sociedade civil e estruturas coligadas nas escolas. Ensaio: Avaliação e Políticas Públicas em Educação. Rio de Janeiro, v. 14, nº 50, p. 27-38, jan./mar., 2006.

GOMES, I. L. Formação de mediadores em museus de ciência. 2013. 140 f. Dissertação (Mestrado em Museologia e Patrimônio) UNIRIO; MAST, 2013.

GOMES, I. L.; CAZELLI, S. Formação de mediadores em museus de ciência: saberes e práticas. Ensaio Pesquisa em Educação em Ciências (Belo Horizonte), v. 18, n. 1, p. 23-46, 2016.

GOMES DA COSTA, A. Os "explicadores” devem explicar? In: MASSARANI, L.; MATTEO M.; RODARI P. (org.). Diálogos \& ciência: mediação em museus e centros de Ciência. - Rio de Janeiro: Museu da Vida/Casa de Oswaldo Cruz/Fiocruz, p. 27-31. 2007.

HAMBURGER, E. W. A popularização da ciência no Brasil. In.: CRESTANA, S. Educação para a ciência: curso para treinamento em centros e museus de ciências. São Paulo: Editora da Física, p. 31-40, 2001.

JACOBUCCI, D. F. C. Contribuições dos espaços não-formais de educação para a formação da cultura científica. Em Extensão, Uberlândia, v. 7, p. 55-66, 2008. 
LARROSA, J. Notas sobre a experiência e o saber da experiência. Revista Brasileira de Educação, n. 19, jan./abr., p. 20-28, 2002.

MARANDINO, M. Interfaces da relação museu-escola. Caderno Catarinense de Ensino de Física. v. 18, n.1: p. 85-100, abr., 2001.

MARANDINO, M. Ação educativa, aprendizagem e mediação nas visitas aos museus de ciências. In: MASSARANI, L. (org.) Workshop Sul Americano e Escola de Mediação em Museus e Centros de Ciências. Rio de Janeiro: Museu da Vida/Casa Oswaldo Cruz/Fiocruz, p. 21-28, 2008.

MASSARANI, L.; MERZAGORA, M.; RODARI, P. (orgs.) Diálogos \& ciência: mediação em museus e centros de Ciência. - Rio de Janeiro: Museu da Vida/Casa de Oswaldo Cruz/Fiocruz, 2007.

MOITA, M. C. Percursos de formação e de trans-formação. In.: NÓVOA, A. Vidas de professores. $2^{\text {a }}$ Ed.: Editora Porto, p. 111-140, 2000.

MOURA, A. F.; LIMA, M. G. A reinvenção da roda: roda de conversa: um instrumento metodológico possível. Revista Temas em Educação, João Pessoa, v.23, n.1, p. 98-106, jan./jun., 2014.

NÓVOA, A. Profissão Professor. Porto; Ed. Porto; Portugal. 1999.

NÓVOA, A. Vidas de professores. Portugal: $2^{\text {a }}$ Ed. Porto, p. 11-30, 2000.

NÓVOA. A. Por uma formação de professores construída dentro da profissão. In: NÓVOA, A. Professores: Imagens do futuro presente. Lisboa: Educa, p. 25-46, 2009.

OVIGLI, D. F. B. Panorama das pesquisas brasileiras sobre educação em museus de ciências. Rev. Bras. Estud. Pedagog. Brasília, v. 96, n. 244, p. 577-595, set./dez., 2015.

PAVÃO, A. C.; LEITÃO, A. Hands-on? Minds-on? Hearts-on? Social-on? Explainers-on! In: MASSARANI, L.; MERZAGORA, M.; RODARI, P. (orgs.) Diálogos \& ciência: mediação em museus e centros de Ciência. - Rio de Janeiro: Museu da Vida/Casa de Oswaldo Cruz/Fiocruz, p. 39-46, 2007.

PINTO, S.; GOUVÊA, G. Mediação: Significações, usos e contextos. Revista Ensaio - Belo Horizonte. v.16, n. 02, p. 53-70, mai./ago., 2014.

QUEIROZ, G.; KRAPAS, S; VALENTE, M. E.; DAVID, E.; DAMAS, E.; FREIRE, F. Construindo Saberes da Mediação na Educação em Museus de Ciências: O Caso dos Mediadores do Museu de Astronomia e Ciências Afins/ Brasil. In: Revista Brasileira de Pesquisa em Ensino de Ciências. v. 2, n. 2, p. 77-88, 2002.

RODARI, P.; MERZAGORA, M. Mediadores em museus e centros de ciência: Status, papéis e capacitação. Uma visão geral europeia. In: MASSARANI, L.; MERZAGORA, M.; RODARI, P. (orgs.) Diálogos \& ciência: mediação em museus e centros de Ciência. - Rio de Janeiro: Museu da Vida/Casa de Oswaldo Cruz/Fiocruz, p. 7-20, 2007.

TARDIF, M.; RAYMOND, D. Saberes, tempo e aprendizagem do trabalho no magistério. Educação \& Sociedade, ano XXI, n⿳ำ 73, dez., 2000.

TARDIF, M. Saberes docentes e formação profissional. 5ª Ed. - Petrópolis, RJ: Vozes, 2002. VITÓRIA. Lei no 5.397 , de 24 de setembro de 2001. Cria a Escola da Ciência - Física e a Escola da Ciência - Biologia/História. Vitória, 2001. 
VITÓRIA. Decreto 17.015, de 02 de maio de 2017. Estabelece a forma de organização e regulamenta o funcionamento das Unidades Administrativas da Secretaria de Educação e dá outras providências. Diário Oficial do Município de Vitória do Estado do Espírito Santo, Edição n⿳0 680. Vitória, 2017.

WAGENSBERG, J. Principios fundamentales de la museología científica moderna. Cuaderno Central. número 55, abr.-jun., 2001.

ZUCOLOTTO, M. A. S.; WEILER JÚNIOR, I.; QUEIROGA, P.; CONTI, R. F.; BISCH, S. M.; SOUZA, E. M.; FERRACIOLI, L. Escola da Ciência Física: Ciência, Educação e Cultura no Município de Vitória, ES. In.: FERRACIOLI, L. Espaços Não Formais de Educação: Educação em Ciência, Tecnologia \& Inovação na região Metropolitana de Vitória, ES. São Paulo: Mandacaru, p. 22-25, 2011. 